\title{
Social aetiology of violent deaths in Swedish children and youth
}

\author{
A Hjern, S Bremberg
}

J Epidemiol Community Health 2002;56:688-692

See end of article for authors' affiliations

......................

Correspondence to: Dr S Bremberg, Department of Public Health Sciences, Karolinska Institute,

National Institute of Public

Health, SE-10352

Stockholm, Sweden,

Sweden;

sven.bremberg@telia.com

Accepted for publication

3 December 2001 conditions for the main causes of injury deaths Study objective: To describe the contribution of
in Swedish children and youth aged $5-25$ years.

Design: Cohort study. All children below 15 years of age that resided in Sweden 1985 were followed up during 1991-1995. Injury deaths were recorded from The National Cause of Death Register. Information on parental social determinants were collected from various national registers. Connections between the social determinants and an injury death outcome were analysed in multivariate Cox regression models.

Main results: In total 1474 injury deaths were recorded during approximately 8 million person years. In a regression model, with control for sex, year of birth, and residency (urban/rural), the aetiological fraction for parental SES, maternal country of birth, family situation, parental risk factors, and all these factors combined were 13\%, $6 \%, 1.4 \%, 1.3 \%$, and 19\%, respectively. Similar regression models were studied separately for each of the main causes of injury death. The parental social determinants explained $58 \%$ of all homicides, $47 \%$ of all motor traffic injuries, and $30 \%$ of all other traffic injuries while the suicide rate was not affected by these determinants. Parental socioeconomic status was the single most important parental determinant for all major causes of injury.

Conclusions: There was a wide variation of the aetiological fractions of parental social determinants for different causes of injury death. This variation might be used to further investigate the social aetiology of injuries.
A ccidental and intentional injuries are leading causes of death in children and youth. Socioeconomic conditions are determinants for this health problem. The rate of injury deaths has been reported to be two to three times higher in low socioeconomic status groups as compared with high status groups, in Australia, ${ }^{1}$ Canada, $^{2}$ New Zealand, ${ }^{3}$ Sweden, ${ }^{4} \mathrm{UK}^{5}{ }^{56}$ and USA. ${ }^{78}$ Most reports only describe odds ratios (OR) for different unfavourable social conditions. Certain uncommon social exposures might give high odds ratios but explain little of the total incidence. Aetiological fractions (AF) ${ }^{9}$ take the occurrence of different exposures into account. AF will therefore describe the contribution of different social causes in a better way. Yet, assessments of social determinants have seldom been presented as AF.

Injury is a heterogeneous phenomenon. Thus, social conditions might contribute more to certain forms of injuries than to others. Understanding of the variation in social causality, between different forms of injuries, might help to explain the mechanism that conveys the effects of social disadvantage. Yet, cause specific social class mortality differentials have only been described by a few authors, including Roberts who studied injury mortality of children aged 0-15 years in England and Wales 1985-92. ${ }^{5}$ He found that the OR, when social class $\mathrm{V}$ is compared with social class I, varied between $\mathrm{OR}=16.3$ for injury deaths attributable to fire, $\mathrm{OR}=5$ for drowning and suffocation deaths, and $\mathrm{OR}=1.6$ for motor vehicle traffic accidents deaths. No information is given on AF.

The objective of this study is to describe the contribution of social conditions for the main causes of accidental and intentional injures in Swedish children and youth aged 5-25 years.

\section{POPULATION AND METHODS}

The study population consisted of all children below 15 years of age that resided in Sweden 1985 according to the census that was carried out that year. These children were accordingly born in the years 1970-1985. Thus, the participants were 5-25 years of age at the time of their death.

The variables for the outcomes in the study were created from data on underlying cause of death (ICD-9 chapter XVII), from the National Cause of Death Register for the years 19911995. Motor traffic injury deaths include cycle or pedestrian injuries when a motor vehicle is involved. Suicide deaths included certain (E850-E859) as well as suspected (E880E889) suicides.

In Sweden, all people are identified by unique identification numbers. These numbers have been used to link The National Cause of Death Register with information on social conditions that is available in other registers. The social determinants that were studied, and their origin, are listed in table 1.

The connection between the social determinants and the outcome, was analysed by means of multivariate Cox regression analysis of person years in the study with presentations of OR and 95\% confidence intervals (CI) for these odds ratios. Person years were calculated with the aid of annual data on immigration from the Swedish Tax and Enumeration Surveys 1991-95, and monthly data on deaths from the National Cause of Death Register. All multivariate models were adjusted to year of birth as a continuous variable, place of residence as a three category dummy variable (large city, small city, rural), and the sex of the child. AF were calculated by the formula $\mathrm{AF}=$ (the proportion exposed of the deceased $) \times((\mathrm{OR}-1) / \mathrm{OR})$.

\section{RESULTS}

The average child population was 1591271 . Thus, the study comprised approximately 7.6 million person years. The total number of deaths was 2413. Of these 1474 were attributable to injuries. Thus, the injury mortality was $19.3 / 100000$ person years. Some $10.6 \%$ of all injury deaths occurred at $<10$ years of age, $13.6 \%$ at $10-<15$ years of age, $47.3 \%$ at $15-<20$ years of 
Table 1 Sources of the determinants that were studied

\begin{tabular}{|c|c|c|c|}
\hline Determinant & Informant & Year of recording & Source of information \\
\hline Parental SES: occupation of head of household & Head of household & 1985 & National census \\
\hline Maternal country of birth & Mother & 1985 & National census \\
\hline $\begin{array}{l}\text { Family situation; single or two parent household, recent } \\
\text { divorce, or recent death of parent }\end{array}$ & Head of household & 1985 and 1990 & $\begin{array}{l}\text { National census and Cause of } \\
\text { Death Register }\end{array}$ \\
\hline $\begin{array}{l}\text { Parental hospital admission for psychiatric, alcohol or drug } \\
\text { abuse diagnoses }\end{array}$ & Mother and father & $1987-1990$ & $\begin{array}{l}\text { Swedish Hospital Discharge } \\
\text { Register }\end{array}$ \\
\hline Parent sentenced to jail & Mother and father & 1973-1993 & National Register of Court Statistics \\
\hline Population density at residency & - & 1990 & National census \\
\hline $\begin{array}{l}\text { Hospital admission for alcohol abuse, drug abuse, } \\
\text { psychiatric care and suicide attempts diagnoses }\end{array}$ & $\begin{array}{l}\text { The physician responsible for the } \\
\text { discharge }\end{array}$ & $1987-1990$ & $\begin{array}{l}\text { Swedish Hospital Discharge } \\
\text { Register }\end{array}$ \\
\hline Sentenced to jail & $\begin{array}{l}\text { The judge responsible for the } \\
\text { sentence }\end{array}$ & 1988-1993 & National Register of Court Statistics \\
\hline Alcohol and drug use at time of death & $\begin{array}{l}\text { The physician responsible for the } \\
\text { death certificate }\end{array}$ & $1991-1995$ & $\begin{array}{l}\text { National Cause of Cause of Death } \\
\text { Register }\end{array}$ \\
\hline
\end{tabular}

\section{Table 2 Causes of injury death}

\begin{tabular}{llll}
\hline Cause of death & $\begin{array}{l}\text { Number of } \\
\text { deaths }\end{array}$ & $\begin{array}{l}\text { Deaths per } \\
\text { person } \\
\text { years }\end{array}$ & Percentage \\
\hline Suicide & 524 & 6.8 & 35.5 \\
Motor traffic injury & 386 & 5.1 & 26.1 \\
Other traffic injury & 256 & 3.4 & 17.3 \\
Non-traffic accidental injury & 253 & 3.3 & 17.1 \\
Homicide & 58 & 0.8 & 3.9 \\
All injuries & 1477 & 19.3 & 100 \\
\hline
\end{tabular}

age, and in the remaining $28.4 \%$ at $20-25$ years of age. Some $71.9 \%$ of the diseased were males and $28.9 \%$ females. Traffic injuries, in motor traffic and other ways, was the most common cause of death (43\%) followed by suicides (36\%), see table 2 .

Sex, year of birth, and population density in the residency areas were studied as background determinants, see table 3 . All causes of injuries were more common among males. The difference between the sexes was most obvious for non-traffic accident injuries, males versus females, $\mathrm{OR}=3.9$, and least apparent for homicides, $\mathrm{OR}=1.7$. For most causes of injury death, there was a continuous gradient over the cohorts with the highest risk in the oldest cohort. This gradient was steepest for suicides and motor traffic deaths, $\mathrm{OR}=88.9$ and 13.7, respectively. Motor traffic injury deaths and homicide deaths, however, were most common in the cohort born 1973-75, 14-22 years old at the time of their death. Injuries were slightly more common in rural areas, $\mathrm{OR}=1.2$. The differences was mainly caused by an increased risk of motor traffic injuries for young people living in rural areas, $\mathrm{OR}=2.0$.

The importance of four groups of parental related social determinants, have been studied in two logistic regression models, table 4 . The four groups were parental SES, maternal country of birth, family situation, and parental risk factors. In Model 1 the determinants were analysed separately and controlled for sex, year of birth, and residency. In Model 2 all determinants, and sex, year of birth, and residency, have been included.

A low parental SES resulted in an increased risk of injury death. The risk of injury in young people of parents with the lowest parental SES OR was 1.3 (Model 1). In Model 2, when all determinants have been included and controlled for sex, year of birth, and residency, the ORs for this group was slightly lower, 1.3. The combined AF for the increased risk conferred by a parent SES below the highest SES was $13.4 \%$ (Model 2). The risk of injury in young people born to mothers with an origin outside Sweden resulted both in increased and decreased risks, depending of the mother's country of birth. Western European origin resulted in an increased risk while southern European and non-European origin was protective. Overall, a non-Swedish origin did not result in an increased risk. Certain family situations increased the risk of an injury death. This was most apparent for families where the mother had died, $\mathrm{OR}=2.0$, or single household, $\mathrm{OR}=1.5$ (Model 2). Yet, the combined AF for all less usual family situations was

Table 3 Sex, year of birth, and population density

\begin{tabular}{|c|c|c|c|c|c|c|c|c|c|c|c|c|c|c|}
\hline \multirow[b]{2}{*}{ Determinant } & \multirow{2}{*}{$\begin{array}{l}\text { Age at } \\
\text { death } \\
\text { (years) }\end{array}$} & \multirow{2}{*}{$\begin{array}{l}\text { Population } \\
\text { share (\%) }\end{array}$} & \multicolumn{2}{|c|}{ All injury } & \multicolumn{2}{|c|}{ Suicide } & \multicolumn{2}{|c|}{ Motor traffic } & \multicolumn{2}{|c|}{ Other traffic } & \multicolumn{2}{|c|}{$\begin{array}{l}\text { Non } \\
\text { traffic-accidental }\end{array}$} & \multicolumn{2}{|c|}{ Homicide } \\
\hline & & & OR & $\mathrm{Cl}$ & OR & $\mathrm{Cl}$ & OR & $\mathrm{Cl}$ & OR & $\mathrm{Cl}$ & OR & $\mathrm{Cl}$ & OR & $\mathrm{Cl}$ \\
\hline \multicolumn{15}{|l|}{ Sex } \\
\hline Male & & 51.2 & 2.5 & 2.2 to 2.7 & 2.4 & 2.0 to 3.0 & 2.6 & 2.1 to 3.4 & 1.9 & 1.4 to 2.5 & 3.9 & 2.9 to 5.4 & 1.7 & 1.0 to 2.9 \\
\hline Female & & 48.8 & 1.0 & & 1.0 & & 1.0 & & 1.0 & & 1.0 & & 1.0 & \\
\hline \multicolumn{15}{|l|}{ Year of birth } \\
\hline 1970-72 & $17-25$ & 21.0 & 9.4 & 7.3 to 12.0 & 88.9 & 28 to 277 & 13.7 & 7.6 to 24.7 & 3.9 & 2.5 to 6.2 & 3.7 & 2.4 to 5.6 & 3.6 & 1.4 to 8.9 \\
\hline $1973-75$ & $14-22$ & 20.4 & 7.7 & 6.0 to 9.9 & 59.1 & 19 to 185 & 14.4 & 8.0 to 25.9 & 2.9 & 1.8 to 4.7 & 2.9 & 1.8 to 4.5 & 4.4 & 1.8 to 10.8 \\
\hline 1976-78 & $11-19$ & 18.0 & 3.5 & 2.7 to 4.6 & 27.2 & 8 to 86 & 3.4 & 1.8 to 6.7 & 2.7 & 1.7 to 4.5 & 2.0 & 1.3 to 3.3 & 0.8 & 0.4 to 3.0 \\
\hline 1979-81 & $8-16$ & 18.0 & 1.6 & 1.2 to 2.2 & 6.2 & 1.8 to 21 & 2.1 & 1.0 to 4.3 & 1.9 & 1.1 to 3.2 & 0.8 & 0.5 to 1.5 & 0.8 & 0.2 to 3.0 \\
\hline 1982-85 & $8-13$ & 22.7 & 1.0 & & 1.0 & & 1.0 & & 1.0 & & 1.0 & & 1.0 & \\
\hline \multicolumn{15}{|c|}{ Population density at residency } \\
\hline Rural & & 20.6 & 1.2 & 1.1 to 1.4 & 1.2 & 0.9 to 1.5 & 2.0 & 1.4 to 2.6 & 1.2 & 0.8 to 1.7 & 1.1 & 0.8 to 1.5 & 0.4 & 0.2 to 0.9 \\
\hline Other Urban & & 50.6 & 1.0 & 0.9 to 1.2 & 0.9 & 0.7 to 1.1 & 1.5 & 1.2 to 2.0 & 1.2 & 0.9 to 1.6 & 0.9 & 0.6 to 1.1 & 0.4 & 0.2 to 0.6 \\
\hline $\begin{array}{l}\text { Stockholm, } \\
\text { Göteborg, } \\
\text { Malmö }\end{array}$ & & 28.8 & 1.0 & & 1.0 & & 1.0 & & 1.0 & & 1.0 & & 1.0 & \\
\hline
\end{tabular}


Table 4 Logistic regression models for parental determinants and all injury deaths. In Model 1 each variable is analysed separately and adjusted for sex, year of birth, and residency (urban/rural divided in six classes). Model 2 includes all variables, sex, year of birth, and residency (urban/rural divided in six classes)

\begin{tabular}{|c|c|c|c|c|c|c|c|}
\hline \multirow[b]{2}{*}{ Determinant } & \multirow{2}{*}{$\begin{array}{l}\text { Population share } \\
\text { (\%) }\end{array}$} & \multicolumn{3}{|c|}{ Model 1} & \multicolumn{3}{|c|}{ Model 2} \\
\hline & & OR & $\mathrm{Cl}$ & AF $(\%)$ & OR & $\mathrm{Cl}$ & $\operatorname{AF}(\%)$ \\
\hline \multicolumn{8}{|l|}{ Parent SES } \\
\hline Unclassified & 20.2 & 1.4 & 1.1 to 1.6 & 6.7 & 1.3 & 1.1 to 1.6 & 5.9 \\
\hline 1 & 22.0 & 1.3 & 1.1 to 1.6 & 6.9 & 1.3 & 1.1 to 1.6 & 6.1 \\
\hline 2 & 16.4 & 1.1 & 0.9 to 1.3 & 1.3 & 1.1 & 0.9 to 1.3 & 1.3 \\
\hline 3 & 11.0 & 1.1 & 0.9 to 1.3 & 0.7 & 1.0 & 0.8 to 1.3 & 0.2 \\
\hline 4 & 17.1 & 1.0 & 0.8 to 1.2 & 0.2 & 1.0 & 0.8 to 1.2 & 0 \\
\hline 5 & 13.3 & 1.0 & & & 1.0 & & \\
\hline Total & & & & 15.8 & & & 13.4 \\
\hline \multicolumn{8}{|l|}{ Maternal country of birth } \\
\hline Sweden & 88.7 & 1.0 & & & 1.0 & & \\
\hline Finland & 4.6 & 1.0 & 0.8 to 1.3 & 0.0 & 0.9 & -0.7 to 1.2 & 0 \\
\hline Western Europe & 2 & 1.4 & 1.0 to 1.9 & 0.8 & 1.4 & 1.0 to 1.8 & 0.7 \\
\hline Eastern Europe & 1.2 & 1.0 & 0.6 to 1.7 & 0.0 & 0.9 & 0.6 to 1.5 & 0 \\
\hline Southern Europe & 2 & 0.6 & 0.3 to 0.9 & 0 & 0.5 & 0.3 to 0.9 & 0 \\
\hline Non-European & 1.6 & 0.6 & 0.3 to 1.0 & 0 & 0.5 & 0.3 to 0.9 & 0 \\
\hline Total & & & & 0 & & & 0 \\
\hline \multicolumn{8}{|l|}{ Family situation } \\
\hline Single household & 6.7 & 1.6 & 1.4 to 1.9 & 3.9 & 1.5 & 1.3 to 1.8 & 3.4 \\
\hline Recent divorce & 7.0 & 1.4 & 1.0 to 1.8 & 2.7 & 1.2 & 1.0 to 1.4 & 1.3 \\
\hline Recent new step parent & 2.3 & 1.2 & 1.0 to 1.5 & 0.5 & 1.3 & 1.0 to 1.7 & 0.7 \\
\hline Mother died & 0.4 & 2.1 & 1.2 to 3.5 & 0.4 & 2.0 & 1.2 to 3.3 & 0.4 \\
\hline Father died & 0.9 & 1.2 & 0.7 to 1.8 & 0.2 & 1.1 & 0.7 to 1.7 & 0.1 \\
\hline Two parent household & 86.4 & 1.0 & & & 1.0 & & \\
\hline Total & & & & 7.7 & & & 5.8 \\
\hline \multicolumn{8}{|l|}{ Parental risk factors } \\
\hline Alcohol admission: yes & 1.5 & 0.9 & 0.6 to 1.3 & 0 & 0.8 & 0.5 to 1.2 & 0 \\
\hline Drug abuse admission: yes & 0.3 & 1.2 & 0.5 to 2.7 & 0.0 & 1.1 & 0.5 to 2.6 & 0.0 \\
\hline Psychiatric admission: yes & 1.7 & 1.2 & 0.9 to 1.8 & 0.4 & 1.2 & 0.8 to 1.7 & 0.3 \\
\hline Mother imprisoned: yes & 0.4 & 3.5 & 2.3 to 5.5 & 0.9 & 3.4 & 2.2 to 5.3 & 0.9 \\
\hline Father imprisoned: yes & 5.3 & 1.1 & 0.9 to 1.4 & 0.7 & 1.1 & 0.8 to 1.3 & 0.3 \\
\hline None of the above & 90.8 & 1.0 & & & 1.0 & & \\
\hline Total & & & & 1.9 & & & 1.3 \\
\hline
\end{tabular}

Table 5 Aetiological fraction of parental determinants for the major causes of injury death according to Model 2

\begin{tabular}{|c|c|c|c|c|c|c|}
\hline \multirow[b]{2}{*}{ Causes of death } & \multirow[b]{2}{*}{$\begin{array}{l}\text { Number of } \\
\text { deaths }\end{array}$} & \multicolumn{4}{|c|}{ Total AF (\%) in groups of parent determinants } & \multirow[b]{2}{*}{$\begin{array}{l}\text { Sum of all AF } \\
(\%)\end{array}$} \\
\hline & & Parent SES & $\begin{array}{l}\text { Maternal } \\
\text { country of birth }\end{array}$ & Family situation & $\begin{array}{l}\text { Parental risk } \\
\text { factors }\end{array}$ & \\
\hline Suicides & 524 & 0 & 0 & 11.1 & 2.7 & 0 \\
\hline Motor traffic injuries & 386 & 42.5 & 0 & 7.4 & 0.3 & 46.7 \\
\hline Other traffic injuries & 256 & 36.4 & 0 & 0 & 0 & 29.9 \\
\hline Non-traffic accidental injuries & 253 & 17.6 & 0 & 5.0 & 1.4 & 24.8 \\
\hline Homicides & 58 & 28.5 & 2.8 & 18.4 & 8.3 & 58.0 \\
\hline All injury deaths & 1477 & 13.4 & 0 & 5.8 & 1.3 & 19.1 \\
\hline
\end{tabular}

only 5.8\% (Model 2). Five parental risk factors were studied. Most affected the risk of injury in their children only slightly . Maternal imprisonment, however, had marked effects, $\mathrm{OR}=3.4$ (Model 2). Yet, the total aetiological fractions for parental risk factors was only $1.3 \%$ (Model 2). The AF combined for all four groups of risk factors was $21.9 \%$ (Model 2).

In table 5, AF for the parental social determinants have been calculated separately for each of the main causes of injury death. The assessments are based on logistic models with all determinants included with control for sex, year of birth and residency, as in Model 2, table 4. Distinct variations appear between the main causes of death.

For suicides, the cumulated AF for all determinants was 0 . The separate groups of parental determinants, however, affected the rate but in different directions. An aberrant family situation, increased the risk, $\mathrm{AF}=11.1 \%$. Single parent households status contributed most, $\mathrm{AF}=5.7 \%$ (not shown in table 5). Yet, a high parental SES increased the risk of suicide. In order to estimate the magnitude of this effect, the cumulated AF was calculated with OR set $=1$ for young people with parent SES = unclassified. The cumulated AF found was $12.9 \%$ (not shown in table 5 ).

The rate of motor traffic injuries was markedly affected by a low parental SES, $\mathrm{AF}=42.5 \%$ and by the family situation, $\mathrm{AF}=7.4 \%$. For children of parents in the lowest SES (group 1) OR was 1.9 (CI 1.3 to 2.9 ) and $\mathrm{AF}=17.0 \%$ (data not shown). Similar patterns appeared for other traffic injuries and non-traffic accidental injuries and that both were affected by low parental SES, $\mathrm{AF}=36.4 \%$, and $\mathrm{AF}=17.6 \%$, respectively, and by the family situation.

The risk factors for homicides formed a specific pattern. All parental risk factors increased the risk and these risk factors combined explained more than half of all homicides, $\mathrm{AF}=58 \%$. A low parental SES and the family situation explained most. 
Table 6 Determinants directly related to the deceased individual. All violent deaths

\begin{tabular}{llll}
\hline Determinant & $\begin{array}{l}\text { Fraction } \\
\text { exposed (\%) }\end{array}$ & OR (CI) & AF (\%) \\
\hline Alcohol abuse & 0.2 & $2.0(1.0$ to 3.8$)$ & 0.2 \\
Drug abuse & 0.0 & $2.1(1.2$ to 7.8$)$ & 0.1 \\
Psychiatric care & 0.5 & $3.8(2.6$ to 5.5$)$ & 1.4 \\
Suicide attempt & 0.5 & $6.7(5.2$ to 8.7$)$ & 2.9 \\
Jail sentence & 0.3 & $3.2(2.4$ to 4.3$)$ & 0.7 \\
Total & & & 5.2 \\
\hline
\end{tabular}

\begin{tabular}{llll}
\multirow{2}{*}{$\begin{array}{l}\text { Table } 7 \\
\text { Register of alcohol or drugs involved in cause of death }\end{array}$} \\
\hline \multirow{4}{*}{$\begin{array}{l}\text { Number of } \\
\text { Causes of death }\end{array}$} & $\begin{array}{c}\text { Notation of } \\
\text { deaths }\end{array}$ & alcohol (\%) & drugs (\%) \\
\hline Suicides & 524 & 4.8 & 2.3 \\
Motor traffic injuries & 386 & 3.8 & 1.2 \\
Other traffic injuries & 256 & 1.2 & 0.0 \\
Non-traffic accidental injuries & 253 & 11.7 & 5.8 \\
Homicides & 58 & 4.3 & 1.5 \\
All injury deaths & 1477 & 4.3 & 1.5 \\
\hline
\end{tabular}

Social determinants that were directly related to the deceased individual were also studied. The AF for none of these determinants exceeded $2.9 \%$, see table 6 . The maximal AF that was found when each cause of death was analysed separately, was $\mathrm{AF}=6.0$ for previous suicide attempts studied as a risk factor for suicides and $\mathrm{AF}=4.1$ for sentence to jail as a risk factor for homicide (data not shown).

The importance of alcohol and drugs exposure at the time of death was finally studied for each of the major causes of injury, see table 7. Alcohol and drug related exposures were most common for non-traffic accidental injuries. Notation of use of alcohol was two to three times more common than use of drugs.

\section{DISCUSSION}

Parental related social determinants explained only 19.2\% of all injury deaths in this study of mainly adolescents and young adults $(86.4 \%$ aged $15-25)$. Yet, there was a wide variation between different causes of injury death. Fifty eight per cent of all homicide was explained by these social determinants and $46.7 \%$ of all motor traffic injuries. Yet, the suicide rate was not at all explained that way. Injury death is obviously a heterogeneous phenomenon. Thus, it is problematic to describe the social aetiology of injures with all causes aggregated.

Parental SES was the single most important parental determinant. It explained $42.5 \%$ of all motor traffic injures, $36.4 \%$ of all other traffic injuries, and $28.5 \%$ of all homicides. The social gradient for motor traffic injures is probably not related to a more intense use of cars in low SES group. A peak in Sweden of all motor traffic injury deaths at about 24 years in age ${ }^{10}$ indicate that the use of cars is not restricted to high SES groups.

Parental SES is not an ideal assessment of the SES in this age group. During growth young people gradually become independent of their parents. This is reflected in a decreased connection by age between parental SES and mortality and morbidity. ${ }^{11}$ Thus, if SES was based on information that directly reflected the living conditions of the young persons themselves, a steeper social gradient might be found.

\section{Key points}

- There was a wide variation of the aetiological fractions of parental social determinants for different causes of injury death.

- There was no significant cumulated effect of parental determinants on the rate of suicides. A low parental SES diminished the risk, and an aberrant family situation increased the risk.

- $35 \%-43 \%$ of all traffic injury deaths might be explained by low parental SES

- Generally, a non-Swedish origin had little effect on the risk of injury death. A maternal origin in a country outside Europe was protective.

The remaining parental determinants seemed to have relatively little importance. They were most significant for the intentional injury deaths. Eleven per cent of all suicides and $18.4 \%$ of all homicides were explained by the family situation. The remaining two groups of variables, maternal country of birth and parental risk factors seemed to be unimportant both for intentional and unintentional injuries.

Individual exposures of the deceased explained only small parts of the injury risks. This finding may partly be explained by the method for assessment of some exposures. In this age group, few have been admitted to a hospital because of alcohol, drug, psychiatric problems, and suicide attempts. Yet, also assessments of alcohol and drug use at the time of death yielded low figures. Some $86.4 \%$ of all deceased in the study were $>15$ years of age. At this age most people, who ever consume alcohol or drugs, have already started their use. ${ }^{12}$ Thus, the limited contribution of drug alcohol use for violent injuries might not be explained by the low age of the population that was studied.

The results are affected by the quality of the information that was obtained from the registers and the quality of the socioeconomic indicators that were was used. Swedish law demands that all deaths, where a violent cause of death is obvious or suspected, are investigated by a forensic medical officer. Evaluations of Swedish cause of death statistics have not demonstrated any significant socioeconomic bias in classification of violent deaths, so there is little reason to believe that this kind of bias have affected the results of this study. ${ }^{13}$ The index of socioeconomic status applied in this study has been used extensively in studies of health and inequality ${ }^{14}$ and has been demonstrated to be quite effective in describing social position in the Swedish society of residents in the active labour force..$^{15}$ The population in this study, however, is considerably younger than the population in the Swedish active labour force. Most of the deaths are in the transitional age of adolescence and young adulthood, where this index may be a much less satisfactory indicator of the social position of the person.

The interpretation of the AF implies that there is a causal relation between the determinant and the outcome. The choice of determinants was based on this assumption. Yet, the determinants did not fulfil all criteria for causality ${ }^{16}$ That is often true for social exposures in general as experiments can seldom be performed. Yet, there are a good arguments for causal links between these exposures and the injury outcomes as social adversities might increase the risk of injuries both though psychological pathways (for example, stress) and though lack of material resources for protection. ${ }^{17}$ Thus, it seems justified to use calculations of AF for the determinants that were investigate.

When separate AF are added, the total sum might exceed $100 \%{ }^{9}$ This is obviously absurd. This problem might happen when different risk factors reflect the same underlying construct. The method for analysis was designed to counteract this problem. ${ }^{18}$ Thus, the AF were derived from logistic analyses where all determinants were analysed at the same time. 
Therefore, we think that the additions of AF will not overestimate the importance of social factors for injury deaths.

The main strength of the study is the large study population and the high quality ${ }^{19}$ and large variety of Swedish National registers. This made it possible for us to use a multivariate approach where a number of different determinants could be entered into the same model of analysis.

In a previous Swedish study of social determinants for injury deaths in children, Östberg found an $\mathrm{OR}=2.74$ when she compared the injury death rates in children from families with occupation of the head of the household stated "unclassified" with the rates in children from families with "upper non-manual" occupations. ${ }^{4}$ That is markedly higher than the $\mathrm{OR}=1.3$ that was found in a similar analysis in this study. We think that the main cause of the disagreement is a variation in age groups between the studies. Östberg studied 0-12 year old children while this study included individuals 5-25 years of age. The injury deaths in this study are dominated by individuals in their late teens or early 20s. Suicide is the leading cause of injury death in this age group while deaths in $0-12$ year old is dominated by traffic injury deaths. Thus, the variation in social gradients between the two studies might be explained.

The social gradient of injury deaths in this study was markedly less steeply than a British study conducted by Roberts. ${ }^{3}$ Roberts found, for all injury deaths in 0-15 year olds, $\mathrm{OR}=4.61$, when social class $\mathrm{V}$ children were compared with social class I children. Part of the variance might be explained by differences in age groups, as discussed above. Yet, there is probably also a true difference of gradients between Britain and Sweden.

This study indicates that the variation in social gradients for different groups of injuries might be used to investigate social aetiology of injuries. One example might be given. There are two competing views on major mechanism that mediate the effects of social disadvantage on health outcomes. ${ }^{20}$ One view emphasises psychological mediators, for example, stress and drug use, and the other view underlines material conditions. If psychological mechanism was important, then social disadvantage might be expected to affect all kinds of injuries, including suicides and traffic injuries. Yet, such effects were only found for traffic injuries. Thus, it might be argued that it is less likely that the effect of social disadvantage on traffic injuries is mediated by psychological mechanism. Thus, the results from this study might contribute to formulations of hypotheses that can be tested in further studies.

\section{Authors' affiliations}

A Hiern, Department of Paedatrics, Huddinge University Hospital, Karolinska Institutet, Stockholm, Sweden and Centre for Epidemiology, National Board of Health and Welfare, Stockholm, Sweden

S Bremberg, Department of Public Health, Karolinska Institutet, Stockholm, Sweden

Funding: none.

Conflicts of interests: none.

\section{REFERENCES}

1 Jolly DL, Moller JN, Volkmer RE. The socio-economic context of child injury in Australia. J Paediatr Child Health 1993;29:438-44.

2 Dougherty G, Pless IB, Wilkins R. Social class and the occurrence of traffic injuries and deaths in urban children. Can J Public Health 1990;81:204-9.

3 Roberts I, Marshall R, Norton R, et al. An area analysis of child injury morbidity in Auckland. J Paediatr Child Health 1992;28:438-41.

4 Östberg V. The social patterning of child mortality: the importance of social class, gender, family structure, immigrant status and population density. Sociology of Health and Illness 1997;19:415-35.

5 Roberts I. Cause specific social class mortality differentials for child injury and poisoning in England and Wales. J Epidemiol Community Health 1997;51:334-5.

6 Cubbin C, LeClere FB, Smith GS. Socioeconomic status and injury mortality: individual and neighbourhood determinants. J Epidemiol Community Health 2000;54:517-24.

7 Durkin. Low-income neighborhoods and the risk of severe pediatric injury: a small area analysis in the Northern Manhattan. Am J Public Health 1994;84:587-92.

8 Scholer SJ, Mitchel EF Jr, Ray WA. Predictors of injury mortality in early childhood. Pediatrics 1997; 100 (3 Pt 1):342-7.

9 Rothman K, Greenland S. Modern epidemiology. Boston: Little, Brown, 1998.

10 Swedish National Road Adminstration. Statistics on motor traffic accidents. http://www.vv.se

11 West $\mathbf{P}$. Health inequalities in the early years: is there equalisation in youth? Soc Sci Med 1997;44:833-58.

12 Chen K, Kandel DB. The natural history of drug use from adolescence to the mid-thirties in a general population sample. Am J Public Health 1995;85:41-7.

13 Allebeck P, Allgulander C, Henningsohn L, et al. Causes of death in a cohort of 50465 young men-validity of recorded suicide as underlying cohort of 50465 young men-validity of recorded
cause of death. Scand J Soc Med 1991;19:242-7.

14 Whitehead $M$, Evandrou $M$, Haglund $B$, et al. As the health divide widens in Sweden and Britain, what's happening to access to care? BM 1997;315:1006-9.

15 Statistics Sweden. Socioeconomic classification. Meddelande $i$ samordningsfrågor 1982;4 (in Swedish).

16 Hill AB. Principles of medical statistics. 9th edn. Oxford: Oxford University Press, 1971:309-23.

17 Rivara FP. Unintentional injuries. In: Pless IB, ed. The epidemiology of Rivara FP. Unintentional injuries. In: Pless IB, ed. The epidemiology of
childhood disorders. Oxford: Oxford University Press, 1994:369-91.

18 Walter SD. Attributable risk in practice. Am J Epidemiol 1998; 148:41 1-13.

19 Allebeck P, Allgulander C, Henningsohn L, et al. Causes of death in a cohort of 50465 young men-validity of recorded suicide as underlying cause of death. Scand J Soc Med 1991;19:242-7.

20 Lynch J, Smith G, Kaplan G, et al. Income inequality and mortality: importance to health of individual income, psychosocial environment, or material conditions. BMV 2000;320:1200-4. 